\title{
Soluble adenylyl cyclase mediates mitochondrial pathway of apoptosis and ATP metabolism in oyster Crassostrea gigas exposed to elevated $\mathrm{CO}_{2}$
}

Xiudan Wang ${ }^{\mathrm{a}, \mathrm{b}, \mathrm{d}}$, Mengqiang Wang ${ }^{\mathrm{a}}$, Jiachao $\mathrm{Xu}^{\mathrm{a}, \mathrm{d}}$, Zhihao Jia ${ }^{\mathrm{a}, \mathrm{d}}$, Zhaoqun Liu ${ }^{\mathrm{a}, \mathrm{d}}$, Lingling Wang ${ }^{\mathrm{c}}$, Linsheng Song ${ }^{\mathrm{b}, \mathrm{c}, *}$

${ }^{\text {a }}$ Key laboratory of Experimental Marine Biology, Institute of Oceanology, Chinese Academy of Sciences, Qingdao 266071, China

${ }^{\mathrm{b}}$ Functional Laboratory of Marine Fisheries Science and Food Production Process, Qingdao National Laboratory for Marine Science and Technology, Qingdao 266071, China

${ }^{\mathrm{c}}$ Liaoning Key Laboratory of Marine Animal Immunology \& Disease Control, Dalian Ocean University, Dalian 116023, China

${ }^{\mathrm{d}}$ University of Chinese Academy of Sciences, Beijing 100049, China

\footnotetext{
* Corresponding author
}

Linsheng Song

No. 52 Heishijiao street, Dalian 116023, China.

Tel: 86-411-84763173; Fax: +86 41184763306

E-mail addresses: 1shsong@dlou.edu.cn 


\title{
Soluble adenylyl cyclase mediates mitochondrial pathway of apoptosis and ATP metabolism in oyster Crassostrea gigas exposed to elevated $\mathrm{CO}_{2}$
}

Xiudan Wang ${ }^{\mathrm{a}, \mathrm{c}}$, Mengqiang Wang ${ }^{\mathrm{a}}$, Jiachao $\mathrm{Xu}^{\mathrm{a}, \mathrm{c}}$, Zhihao $\mathrm{Jia}^{\mathrm{a}, \mathrm{c}}$, Zhaoqun $\mathrm{Liu}^{\mathrm{a}, \mathrm{c}}$, Lingling Wang ${ }^{\mathrm{b}}$, Linsheng Song ${ }^{\mathrm{b}, *}$

${ }^{a}$ Key laboratory of Experimental Marine Biology, Institute of Oceanology, Chinese Academy of Sciences, Qingdao 266071, China

${ }^{\mathrm{b}}$ Functional Laboratory of Marine Fisheries Science and Food Production Process, Qingdao National Laboratory for Marine Science and Technology, Qingdao 266071, China

${ }^{\mathrm{c}}$ Liaoning Key Laboratory of Marine Animal Immunology \& Disease Control, Dalian Ocean University, Dalian 116023, China

${ }^{\mathrm{d}}$ University of Chinese Academy of Sciences, Beijing 100049, China

\begin{abstract}
Ocean acidification (OA) has deleterious impacts on immune response and energy homeostasis status of Mollusca. In the present study, the apoptosis ratio of hemocytes and the adenosine triphosphate (ATP) allocation in gill tissues were determined after Pacific oysters Crassostrea gigas were exposed to elevated $\mathrm{CO}_{2}$ environment $(\mathrm{pH}=7.50)$ for 16 days.. The apoptosis ratio in $\mathrm{CO}_{2}$ exposure group (35.2 \%) was
\end{abstract}


significantly higher $(p<0.05)$ than that in the control group, and the increased apoptosis ratio induced by elevated $\mathrm{CO}_{2}$ could be significantly inhibited $(p<0.05)$ by KH7, a specific inhibitor of a bicarbonate sensor soluble adenylyl cyclase (sAC). After $\mathrm{CO}_{2}$ exposure, sAC in oyster $(\mathrm{CgsAC})$ was found to be clustered with mitochondria in the cytoplasm, and the pro-caspase-3 was cleaved into two small fragments. Moreover, the activities of caspase- 3 and caspase- 9 also increased post $\mathrm{CO}_{2}$ exposure and these increases could be inhibited by KH7. However, the activities of caspase- 8 did not change significantly compared with that in the control group. After $\mathrm{CO}_{2}$ exposure, the ATP content in the gill increased significantly $(p<0.05)$ and such increase could also be inhibited by KH7. The ATP content in purified gill mitochondria decreased significantly $(p<0.05)$ after $\mathrm{CO}_{2}$ exposure, which was also inhibited by KH7. These results implied that the elevated $\mathrm{CO}_{2}$ could activate the mitochondria-CgsAC pathway of apoptosis and ATP metabolism in oyster, and this pathway played essential roles in maintaining the homeostasis and the balance of energy metabolism in response to OA.

Keywords: Crassostrea gigas; Elevated $\mathrm{CO}_{2}$; Apoptosis; ATP; Soluble adenylyl cyclase; Mitochondria 


\section{Introduction}

Pacific oyster (Crassostrea gigas) is one of the most widely cultured species in the second largest animal phylum Mollusca [1]. They are successful colonizers of estuaries and intertidal zones where environmental balance is easily interfered by series of environmental stresses, such as temperature, salinity, pathogens and carbonic chemistry disturbance [2-4]. As important marine calcifiers and ecosystem engineers in the marine environment, oysters are regarded as model organisms in the investigation of marine environmental stresses such as dry exposure, temperature, heavy metal, and low oxygen [5-7]. Recently, the rising of atmospheric carbon dioxide is predicted to cause the decrease of ocean $\mathrm{pH}$ by about $0.3-0.4$ units at the end of this century, which is termed ocean acidification (OA) [8]. It changes the carbonate chemistry of seawater (i.e. speciation of inorganic carbon) and reduces calcium carbonate saturation state [9]. OA could pose severe impacts on shell-forming marine organisms from plankton to benthic mollusks, echinoderms, and corals [10]. There are various reports about the negative effects of OA on oysters, such as on fertilization, larval development, growth, immune response and energy metabolism [5, $11-14]$.

Apoptosis, a type of programmed cell death process, plays crucial roles during development and aging in both vertebrates and invertebrates. It is involved in immune responses against biotic stresses like various pathogens and adaptive responses to environmental stresses $[15,16]$. The apoptosis pathway can be divided into extrinsic 
or death receptor pathway and intrinsic or mitochondrial pathway [17]. Environmental contaminations such as heavy metals could trigger the intrinsic apoptosis pathway. For example, $\mathrm{Cd}$ induced mitochondrial apoptosis pathway in the hepatopancreas of freshwater crab Sinopotamon yangtsekiense [18] and in the gill cells of Mytilus edulis [19]. It has been reported that OA could increase the apoptosis ratio of hemocytes in oyster [11]. However, the underlying mechanism of the regulation has not yet been well understood.

Energy metabolism is critical to maintain physiological homeostasis in response to environmental changes, such as oxygen deficiency, temperature stress, salinity, pollution and $\mathrm{OA}[20,21]$. The decreasing of $\mathrm{pH}$ value may result in deleterious impacts on energy homeostasis which are closely related to the survival of mollusks $[11,20,22-24]$. For example, exposure to OA may cause the shifts of the energy budget in cells, tissues or the whole organism due to shifted acid-base regulation [25]. The balance of ATP synthesis and consumption plays essential roles in adaptation to environmental stresses [21]. Oysters are filter feeders and their gills are constantly exposed to the outside environment for respiration and filtration, and frequently in contact with the chemically altered water [26]. Environmental stresses like hypercapnia, hypoxia, air exposure or copper treatment could affect the energy metabolic activities in gill $[27,28] . \mathrm{CO}_{2}$ exposure may cause metabolic alteration to maintain sufficient energy for the necessary physiological processes such as ion transportation and acid-base regulation [20, 22, 23, 29]. Thus, the ATP allocation in gill is worthy of investigating and it might provide a better understanding of 
biological responses to $\mathrm{OA}$.

Soluble adenylyl cyclase (sAC) is a conserved bicarbonate sensor and also an important intracellular source of signaling molecule cyclic AMP (cAMP) [30, 31]. It has been demonstrated to control mitochondria-dependent apoptosis in rat cardiomyocytes and coronary endothelial cells and could serve as a metabolic sensor modulating ATP generation in response to nutrient availability [32-34]. When mollusks are exposed to the elevated $\mathrm{CO}_{2}$, the transport of $\mathrm{H}^{+}$and $\mathrm{HCO}_{3}{ }^{-}$would be activated to maintain acid-base balance, resulting in accumulation of bicarbonate ions [35]. In our previous study, sAC was identified in oyster (CgsAC) and its involvement in the activation and regulation of physiological processes after $\mathrm{CO}_{2}$ exposure had been evaluated [36]. The purposes of the present study were (1) to explore the effects of $\mathrm{CO}_{2}$ exposure on apoptosis ratio of hemocytes and ATP allocation in gill; (2) to clarify the roles of $\mathrm{Cgs} \mathrm{AC}$ in the $\mathrm{CO}_{2}$ exposure induced apoptosis and ATP allocation, to further understand the regulation mechanism and living strategy of oyster in response to $\mathrm{OA}$.

\section{Materials and methods}

\subsection{Oysters}

Oysters C. gigas were collected from a local farm in Qingdao, China, with average shell length of $13.0 \mathrm{~cm}$. The oysters were pre-punched near the muscle by the side of shell and then cultured in the aerated seawater at about $15{ }^{\circ} \mathrm{C}$ for one week before processing. The experiments were approved by the Qingdao Animal Care and 
Use Committee with a permit number of SCXK (Shandong) 20090007, which complied with the National Institute of Health Guide for the Care and Use of Laboratory Animals.

\section{2. $\mathrm{CO}_{2}$ exposure and inhibitor injection}

Forty-five individuals were randomly divided into control group $(\mathrm{pH}=8.10 \pm 0.05)$ (9 oysters) and $\mathrm{CO}_{2}$ exposure group ( $\left.\mathrm{pH}=7.50 \pm 0.05\right)$ (36 oysters). They were cultured in water tanks with volume of $100 \mathrm{~L}$ continuously bubbled with the ambient air or air- $\mathrm{CO}_{2}$ mixtures as appropriate, and the water was changed every other day to ensure adequate water quality. The new water was pre-bubbled with air- $\mathrm{CO}_{2}$ mixtures and the $\mathrm{pH}$ value was adjusted to 7.50. The $\mathrm{pH}$ value in the $\mathrm{CO}_{2}$ exposure group was controlled using an acidometer (AiKB, Qingdao, China). Oysters in the control group and $\mathrm{CO}_{2}$ exposure group were kept for 16 days under the same culture conditions except the $\mathrm{pH}$ value. During the treatment process, the temperature of the control group was controlled to be $14.9 \pm 0.5{ }^{\circ} \mathrm{C}$ and that of $\mathrm{CO}_{2}$ exposure group was 15.0 $\pm 0.3{ }^{\circ} \mathrm{C}$; salinity of the control group was $32.9 \pm 0.1$ and that of $\mathrm{CO}_{2}$ exposure group was $32.7 \pm 0.1$; the dissolved oxygen of the control group was $7.83 \pm 0.04 \mathrm{mg} / \mathrm{L}$ and that of $\mathrm{CO}_{2}$ exposure group was $7.85 \pm 0.02 \mathrm{mg} / \mathrm{L}$.

Twenty-seven oysters in the $\mathrm{CO}_{2}$ exposure group were used for the inhibitor injection experiment, and they were pre-adapted to the $\mathrm{CO}_{2}$ exposed environment for two days. One hundred microliter of sAC specific inhibitor (KH7, K3394, Sigma-Aldrich, St Louis, MO, USA) with concentration of $5 \mathrm{mM}$ and $0.5 \mathrm{mM}$ was injected into the muscle adductor of each oyster. The final concentrations of KH7 in 
each oyster were calculated to be about $50 \mu \mathrm{mol} \mathrm{kg}-1$ and $5 \mu \mathrm{mol} \mathrm{kg}{ }^{-1}$, respectively (9 oysters in each treatment, the average wet weight of each oyster except the shell was about $10 \mathrm{~g}$ ). The oysters received an injection of $100 \mu \mathrm{L}$ DMSO were used as the negative control (9 oysters). After incubation for another 14 days, gills (including edge, and center) were cut from each individual, snap-frozen in liquid nitrogen, and then stored in $-80{ }^{\circ} \mathrm{C}$ for ATP determination. Fresh gill tissues were cut from oysters for mitochondria isolation. Hemocytes from the oysters in different groups were collected for the determination of apoptosis ratio and immunohistochemistry assay. The tissues and hemocytes from three oysters were pooled as one separate sample, and there are three samples for each tissue.

\subsection{Apoptosis assay by flow cytometry}

The hemolymphs were collected from three oysters in each group, and they were mixed immediately with equal volume of pre-chilled anticoagulant $\left(8 \mathrm{~g} \mathrm{~L}^{-1}\right.$ citric acid, $22 \mathrm{~g} \mathrm{~L}^{-1}$ sodium citrate, $24.5 \mathrm{~g} \mathrm{~L}^{-1}$ glucose), and then centrifuged at $800 \mathrm{~g}, 4{ }^{\circ} \mathrm{C}$ for 10 min. The hemocytes were re-suspended in modified Leibovitz's L-15 mediums (M-L-15, Leibovitz's L-15 mediums with $20.2 \mathrm{~g} \mathrm{~L}^{-1} \mathrm{NaCl}, 0.54 \mathrm{~g} \mathrm{~L}^{-1} \mathrm{KCl}, 0.6 \mathrm{~g} \mathrm{~L}^{-1}$ $\mathrm{CaCl}_{2}, 1 \mathrm{~g} \mathrm{~L}^{-1} \mathrm{MgSO}_{4}, 3.9 \mathrm{~g} \mathrm{~L}^{-1} \mathrm{MgCl}_{2}$ ) (Life Technologies, Carlsbad, CA, USA) and the cell concentration was adjusted to $10^{6} \mathrm{~mL}^{-1}$.

The apoptosis ratio of cells was measured by flow cytometry according to the instruction of Annexin V-Alexa Fluor 488/Propidium Iodide (PI) Apoptosis Assay Kit (KeyGEN BioTECH, Nanjing, China). One hundred microliter of hemocyte suspension was incubated with $5 \mu \mathrm{L}$ Annexin V-Alexa Fluor 488 and $10 \mu \mathrm{L}$ PI in the 
dark for $20 \mathrm{~min}$. The mixture was diluted with $400 \mu \mathrm{L}$ M-L-15 solution and analyzed by a flow cytometer BD FACSAria II (BD Biosciences, Franklin Lakes, NJ, USA). The apoptotic percentage was determined by counting 10,000 cells.

\subsection{Immuno-colocalization of $\mathrm{Cgs} A C$ with mitochondria in hemocyte}

The hemolymphs from six oysters in control and $\mathrm{CO}_{2}$ exposure groups were collected and centrifuged at $800 \mathrm{~g}, 4{ }^{\circ} \mathrm{C}$ for $10 \mathrm{~min}$ to collect the hemocytes. The hemocytes were re-suspended in M-L-15 and the suspension was added onto positively charged slides. After incubated at room temperature for $3 \mathrm{~h}$, the supernatant was discarded and 4\% PFA (Paraformaldehyde diluted in PBS) was added to fix the hemocytes for $15 \mathrm{~min}$. After three times of washing in PBST (0.1\% Tween 20 in PBS, $\mathrm{pH} 7.40$ ), the slides were blocked with $3 \%$ bovine serum albumin (BSA) in PBS at room temperature for $30 \mathrm{~min}$. The supernatant was removed and the slides were incubated with polyclonal antibody of CgsAC (diluted by 1:500 in blocking buffer) and COX IV antibody (diluted by 1:2400 in blocking buffer, Cell Signaling Technology, Beverly, MA, USA) at $37{ }^{\circ} \mathrm{C}$ for $1 \mathrm{~h}$, respectively. After another three times of washing, the slides were incubated with Alexa Fluor 488-labeled goat-anti-mouse antibody (diluted by 1:1000 in blocking buffer) and Alexa Fluor 594-labeled goat-anti-rabbit antibody (diluted by $1: 1000$ in blocking buffer) at $37{ }^{\circ} \mathrm{C}$ for $1 \mathrm{~h}$. Finally, after three times of washing, 4',6-Diamidine-2'-phenylindole dihydrochloride (DAPI, $10 \mathrm{mg} \mathrm{mL}^{-1}$, diluting in PBS by 1:2500, Roche, Basel, Switzerland) was added onto the slides to stain the nucleus. After the last three times of washing, $50 \%$ glycerol was added to seal the slides before observation under Laser 
Scan Confocal Microscope (ZEISS, Oberkochen, Germany).

\subsection{Mitochondria isolation from gill tissues}

The isolation of mitochondria from gill tissues was performed using Tissue Mitochondria Isolation Kit (Beyotime, Shanghai, China) according to the manufacturer's instructions. Protein concentrations were determined with the BCA (bicinchonininc acid) Protein Assay Kit (Beyotime, Shanghai, China) with BSA as standard. The purified mitochondria was used for ATP determination and western blotting.

\subsection{Western blotting}

The protein samples were loaded for SDS-PAGE assay according to previous report [4], and the proteins were electrophoretically transferred on to a nitrocellulose membrane. After blocked with 5\% milk (dissolved in PBST) at room temperature for $1 \mathrm{~h}$, the membrane was incubated with polyclonal antibody at $4{ }^{\circ} \mathrm{C}$ overnight, washed three times with PBST, and then incubated with HRP conjugated secondary antibody at room temperature for $1 \mathrm{~h}$. After three times of washing with PBST, the membrane was visualized by Thermo Scientific SuperSignal kit (Life Technologies, , Carlsbad, CA, USA) and developed by X-ray films. The polyclonal antibodies of CgsAC and CgCaspase- 3 were prepared according to our previous study $[36,37]$. The secondary antibody of goat-anti-mouse $\operatorname{IgG}(\mathrm{ASO03})$ and the polyclonal antibody of $\beta$-tubulin (AC008) were bought from ABclonal (Cambridge, MA, USA). The COX IV antibody was bought from Cell Signaling Technology (4844, Beverly, MA, USA), and the secondary antibody was goat-anti-rabbit IgG (AS014, ABclonal, Cambridge, MA, 
USA).

\subsection{Caspase activity analysis of hemocytes samples}

The caspase-3/8/9 activities of hemocytes samples were detected using caspase-3/8/9 activity assay kits (Beyotime, Shanghai, China) according to the manufacturer's instructions.

\subsection{ATP measurement}

The amount of ATP was measured by the luciferin-luciferase method following the protocols of ATP detection kit (Beyotime, Shanghai, China). Twenty milligram tissue samples were ground with $200 \mu \mathrm{L}$ lysis buffer and centrifuged at $12,000 \times \mathrm{g}, 4{ }^{\circ} \mathrm{C}$ for $5 \mathrm{~min}$ to collect the supernatants. The luminescence of $100 \mu \mathrm{L}$ supernatant sample was assayed in a SYNERGY H1 microplate reader (BioTek, Winooski, VT) together with $100 \mu \mathrm{L}$ ATP detection buffer. The standard curve of ATP concentration was prepared from a known serial concentrations (1 $\mathrm{nM}$ to1 $\mu \mathrm{M})$. The purified mitochondria were ground in the lysis buffer, and the ATP content as well as protein concentration were determined as described above.

\subsection{Statistical analysis}

Results from three technical replicates were expressed as means $\pm \mathrm{SD}(\mathrm{N}=3)$ and analyzed by Statistical Package for Social Sciences (SPSS) 16.0. The significant differences among groups were tested by one-way analysis of variance (ANOVA) and multiple comparisons and the assumptions of ANOVA (normality and homogeneity of variances) were met. The relationship was analyzed by Pearson test. Differences were considered significant at $p<0.05$. 


\section{Results}

\subsection{Apoptosis ratios of hemocytes}

The mean apoptosis ratio in $\mathrm{CO}_{2}$ exposure group was $34.6 \pm 0.6 \%$ (28.3\% apoptosis at early stage and $6.3 \%$ apoptosis/necrosis at late stage), which was significantly higher $(p<0.05)$ than that in control group with ratio of $23.7 \pm 1.2 \%$ (19.8\% apoptosis at early stage and 3.9\% apoptosis/necrosis at late stage) (Fig. 1). Such increased apoptosis ratio was significantly inhibited $(p<0.05)$ by the specific inhibitor of sAC, KH7. The apoptosis ratio of the group injected with $50 \mu \mathrm{mol} / \mathrm{kg}$ KH7 was $12.3 \pm 1.6 \%$ (9.1\% apoptosis at early stage and $3.2 \%$ apoptosis/necrosis at late stage), which was much lower than that in the $\mathrm{CO}_{2}$ exposure group and even lower than that in the control group. Although the ratio of the group injected with 5 $\mu \mathrm{mol} / \mathrm{kg} \mathrm{KH7}(22.2 \pm 0.8 \%)$ was higher than that in the group injected with 50 $\mu \mathrm{mol} / \mathrm{kg} \mathrm{KH} 7$, it was still lower than that in the $\mathrm{CO}_{2}$ exposure group and the control group. For oysters received an injection with DMSO, the apoptosis ratio was $31.6 \pm$ $2.2 \%(21.5 \%$ apoptosis at early stage and $10.1 \%$ apoptosis/necrosis at late stage) which was not significantly different from that in the $\mathrm{CO}_{2}$ exposure group.

\subsection{Immunohistochemistry of CgsAC and mitochondria in hemocytes}

Immunohistochemistry of CgsAC and mitochondria in hemocytes was observed by fluorescence confocal (Fig. 2). CgsAC was labeled by polyclonal antibody of CgsAC and Alexa Fluor 488-labeled goat-anti-mouse antibody, which was observed in green. The positive immunoreactivity of CgsAC (green signal) was observed in both nuclei and cytoplasm and distributed separately in the control group. After $\mathrm{CO}_{2}$ 
exposure, the immunoreactivity of CgsAC was also found in nuclei and cytoplasm, but most of them were clustered together rather than dispersed from each other (Fig. 2). Mitochondria was labeled by polyclonal antibody of COX IV and Alexa Fluor 594-labeled goat-anti-rabbit antibody, which was observed in red. In the control group, the signal of mitochondria distributed separately in the cytoplasm and did not overlap with the signal of $\mathrm{CgsAC}$. After $\mathrm{CO}_{2}$ exposure, the mitochondria seemed to be more concentrated and clustered with CgsAC.

\subsection{Cleavage of Cgcaspase-3 after $\mathrm{CO}_{2}$ exposure and $\mathrm{CgsAC}$ inhibition}

The western blotting of Cgcaspase-3 was conducted after the treatments of $\mathrm{CO}_{2}$ exposure and CgsAC inhibition and tissues from three oysters were pooled as one sample $(\mathrm{N}=1)$ (Fig. 3). The result showed that a proenzyme form of Cgcaspase-3 with the molecular weight of $40 \mathrm{kD}$ was revealed in all the groups including the control group, $\mathrm{CO}_{2}$ exposure group, DMSO injection group and $\mathrm{KH} 7$ injection group. The cleaved forms of Cgcaspase-3, two subunits of active endogenous Cgcaspase-3 with the molecular weight of about $17 \mathrm{kD}$, were revealed in the control group, $\mathrm{CO}_{2}$-exposure group, DMSO injection group and $5 \mu \mathrm{mol} / \mathrm{kg} \mathrm{KH7} \mathrm{injection} \mathrm{group.} \mathrm{But}$ the cleaved forms of Cgcaspase-3 was not detected in the $50 \mu \mathrm{mol} / \mathrm{kg} \mathrm{KH} 7$ injection group.

3.4. Caspase-3/8/9 activity of hemocytes after the treatments of $\mathrm{CO}_{2}$ exposure and CgsAC inhibition

The homogenates of hemocyte were incubated with the caspase substrates for human caspase-3 (Ac-DEVD-pNA, acetyl-Asp-Glu-Val-Asp p-nitroanilide), 
caspase-8 (Ac-IETD-pNA, acetyl-Ile-Glu-Thr-Aspp-nitroanilide) and caspase-9 (Ac-LEHD-pNA, acetyl-Leu-Glu-His-Asp p-nitroanilide) to determine the caspase-3/8/9 activities. It was $27.2 \mathrm{U} / \mathrm{mg}$ protein for caspase-3 (Fig. $4 \mathrm{~A}$ ) in the $\mathrm{CO}_{2}$ exposure group, which was higher than that in the control group (22.6 U/mg protein) $(p<0.05)$. The caspase-3 activity in the $50 \mu \mathrm{mol} / \mathrm{kg} \mathrm{KH} 7$ injection group $(19.0 \mathrm{U} / \mathrm{mg}$ protein) decreased significantly relative to that in the $\mathrm{CO}_{2}$ exposure group $(p<0.05)$, and the treatment with $5 \mu \mathrm{mol} / \mathrm{kg} \mathrm{KH} 7$ also reduced the caspase- 3 activity. The caspase- 9 activity in the $\mathrm{CO}_{2}$ exposure group (9.99 U/mg protein) also increased significantly $(p<0.05)$ relative to that in the control group $(7.62 \mathrm{U} / \mathrm{mg}$ protein). The caspase-9 activity in the $50 \mu \mathrm{mol} / \mathrm{kg} \mathrm{KH} 7$ injection group decreased to $6.13 \mathrm{U} / \mathrm{mg}$ protein which was lower $(p<0.05)$ than that in the $\mathrm{CO}_{2}$ exposure group. In the 5 $\mu \mathrm{mol} / \mathrm{kg} \mathrm{KH} 7$ injection group, the caspase-9 activity decreased to $9.27 \mathrm{U} / \mathrm{mg}$ protein (Fig. 4 B). The changes of caspase-9 activity (Fig. 4 B) in different groups were similar to that of caspase-3, and there were positive relationships between caspase-3 and caspase-9 activity $(r=0.980, p<0.05)$. However, the caspase- 8 activity in $\mathrm{CO}_{2}$ exposure group and $\mathrm{KH} 7$ injection group did not change significantly compared with that in the control group (Fig. 4 C).

\subsection{The distribution of CgsAC in the mitochondria and gill}

The distributions of $\mathrm{CgsAC}, \mathrm{COX}$ IV, and $\beta$-tubulin in mitochondria and tissues of gill were determined by western blotting (Fig. 5).There were two CgsAC bands of $126 \mathrm{kD}$ band and $45 \mathrm{kD}$ revealed in the gill samples, while only one band of $45 \mathrm{kD}$ identified in the purified mitochondria. A $\beta$-tubulin band of $55 \mathrm{kD}$ was only detected 
in the tissue samples but not in the mitochondria samples (Fig. 5). For the COX IV, a band of $20 \mathrm{kD}$ was detected in both the tissue samples and the mitochondria samples.

\subsection{ATP content in the gill tissue and mitochondria samples}

The contents of ATP was $3.15 \mu \mathrm{mol} / \mathrm{g}$ wet tissue in the gill of the $\mathrm{CO}_{2}$ exposure group, which was 1.88 -fold higher $(p<0.05)$ than that in the control group $(1.68$ $\mu \mathrm{mol} / \mathrm{g}$ wet tissue) (Fig. 6 A). After treatment with $50 \mu \mathrm{mol} / \mathrm{kg} \mathrm{KH} 7$, the ATP content was reduced significantly from $3.15 \mu \mathrm{mol} / \mathrm{g}$ wet tissue to $1.94 \mu \mathrm{mol} / \mathrm{g}$ wet tissue, while the injection of $5 \mu \mathrm{mol} / \mathrm{kg} \mathrm{KH7}$ and DMSO did not change ATP content significantly in gill.

The ATP content in the mitochondria purified from fresh gill using mitochondria purification kit also changed significantly after $\mathrm{CO}_{2}$ exposure and treatment with $\mathrm{KH} 7$ (Fig. $6 \mathrm{~B}$ ), which was negatively correlated to the ATP changes in gill tissues. It decreased significantly $(p<0.05)$ from $35.60 \mathrm{nmol} / \mathrm{mg}$ protein to $8.80 \mathrm{nmol} / \mathrm{mg}$ protein (decreased by $75 \%$ ) after $\mathrm{CO}_{2}$ exposure. The treatment with $50 \mu \mathrm{mol} / \mathrm{kg} \mathrm{KH} 7$ significantly increased the ATP content in gill mitochondria sample $(40.05 \mathrm{nmol} / \mathrm{mg}$ protein) compared to that in the $\mathrm{CO}_{2}$ exposure group $(8.80 \mathrm{nmol} / \mathrm{mg}$ protein) ( $p<$ 0.05). There was no significant effect of $5 \mu \mathrm{mol} / \mathrm{kg} \mathrm{KH7}$ and DMSO on ATP content in gill mitochondria.

\section{Discussion}

Extensive evidences have demonstrated the impacts of OA on the physiological and biochemical processes of mollusk, such as metabolism, acid-base status, immune 
response, calcification and protein synthesis [35, 38]. Recently, OA was reported to increase the apoptosis ratio and reactive oxygen species (ROS) production in hemocytes of oyster [11]. Furthermore, OA could also disturb the energy metabolism which thereupon affected the immune competence of bivalves $[5,23]$. The information and underlying mechanisms are necessary to further illustrate the long term adaptation of bivalves. Soluble adenylyl cyclase is a conserved bicarbonate sensor and the source of cAMP, which is involved in the regulation of a series of downstream pathways. CgsAC has been identified in oyster, and it could regulate the physiological status of oyster under $\mathrm{CO}_{2}$ exposure, such as intracellular $\mathrm{pH}$, ROS, phagocytic rate [36], but its roles in regulating apoptosis and ATP metabolism remain unclear.

In the present study, the apoptosis ratio was observed to increase after $\mathrm{CO}_{2}$ exposure for 16 days, indicating that apoptosis pathway could be activated after $\mathrm{CO}_{2}$ stress, and apoptosis might be an adaptive response of oyster to $\mathrm{CO}_{2}$ induced acid stress. In order to understand the role of $\mathrm{CgsAC}$ in apoptosis induced by $\mathrm{CO}_{2}$, the apoptosis ratio was measured after the treatment with $\mathrm{KH} 7$, a specific sAC inhibitor, during the $\mathrm{CO}_{2}$ exposure. The increased apoptosis ratio induced by elevated $\mathrm{CO}_{2}$ was significantly inhibited $(p<0.05)$ by KH7, suggesting a key role of $\mathrm{CgsAC}$ in the $\mathrm{CO}_{2}$ stress-induced apoptosis of hemocytes. After $\mathrm{CO}_{2}$ exposure, the signals of $\mathrm{CgsAC}$ and mitochondria became more concentrated and were clustered in the hemocytes. Previously, sAC participated in the mitochondrial pathway of apoptosis induced by oxysterol treatment in human vascular smooth muscle cells and mediated 
mitochondrial apoptosis of adult rat cardiomyocytes under simulated ischaemia/reperfusion $[33,34]$. In these studies, mitochondrial translocation of sAC was found under anoxic stress which would then lead to a selective activation of protein kinase A (PKA) localized within mitochondrial microdomains. Therefore, the overlap of the signal of $\mathrm{CgsAC}$ and mitochondria suggested that $\mathrm{CgsAC}$ might enter into the mitochondria after $\mathrm{CO}_{2}$ exposure and the mechanism of $\mathrm{CO}_{2}$ effects in apoptosis was proposed to be the mitochondrial apoptosis pathway.

Caspases are a group of cysteine proteases playing crucial roles in apoptosis. They are sub-classified into initiator caspases (caspase-2, 8, 9, 10) and executioner caspases (caspase-3, 6, 7) based on their known roles in apoptosis [37]. The executory step of all the apoptosis pathways is initiated by the cleavage of caspase-3 [15]. Pro-caspase-3 can be activated by upstream caspase-8 [39] and caspase-9 [40], and then mediates death receptor pathway and mitochondrial pathway, respectively. According to previous study [15], these components of the apoptotic pathways are conserved throughout evolution including mollusks. Therefore, the cleavage of caspase- 3 and the activity of caspase 3/8/9 were detected. The result showed that caspase- 3 is activated by $\mathrm{CO}_{2}$ exposure and thus likely to be involved in the observed increase of apoptosis. After $\mathrm{CO}_{2}$ exposure treatment, pro-caspase-3 in oyster was cleaved into two small fragments as previous report [37], and such cleavage was inhibited by $\mathrm{KH} 7$ in a concentration-responsive manner $(\mathrm{N}=1)$. Caspase- 9 is the key protease in the mitochondria-induced apoptosis pathway [18], while Caspase- 8 is the key element in the death-receptor pathway [18]. The activation of caspase- 8 or 
caspase- 9 could further trigger the downstream executioner caspase- 3 and induce cell apoptosis $[15,16]$. In the present study, the caspase- 8 activity in the $\mathrm{CO}_{2}$ exposure group and $\mathrm{KH} 7$ injection group did not change significantly compared to that in control group. It seems that the effect of the $\mathrm{pH}$ and $\mathrm{KH} 7$ on the activation of the apoptotic pathway is not dependent of the death receptors. The positive correlation between caspase- 3 and caspase- 9 activation $(\mathrm{r}=0.980, p<0.05)$ indicated that $\mathrm{CO}_{2}$ exposure might induce apoptosis via the mitochondrial pathway. These results were in agreement with the previous report about the apoptosis in hepatopancreas of crab induced by $\mathrm{Cd}$ exposure [18]. In oyster, the increased activities of caspase-3 and caspase-9 was inhibited by KH7, suggesting that the mitochondrial pathway of apoptosis induced by $\mathrm{CO}_{2}$ exposure could be regulated by CgsAC. During exposure to elevated $\mathrm{CO}_{2}$, the active transport of $\mathrm{H}^{+}$and $\mathrm{HCO}_{3}{ }^{-}$would be stimulated and intracellular $\mathrm{HCO}_{3}{ }^{-}$ions would increase [35], which could lead to the activation of CgsAC. Then downstream PKA might be activated and the CgsAC mediated mitochondrial apoptosis pathway would be stimulated to maintain internal homeostasis. This regulation mechanism should be one of the living strategies of oyster in such complex environment.

A growing number of evidences have been documented about the effects of elevated $\mathrm{CO}_{2}$ exposure on the energy metabolism of marine and estuarine mollusks [5, 22, 23, 41]. In the present study, the ATP content in the gill tissue increased significantly $(p<0.05)$ after $\mathrm{CO}_{2}$ exposure. Similarly, tissue ATP production in Sabella spallanzanii also increased significantly after it was exposed to elevated $\mathrm{CO}_{2}$ 
conditions for 5 days [42]. In sea urchin, ion transport accounted for $11 \%$ to $30 \%$ of the metabolic rate under normal condition, while this ratio increased to a range of $20-46 \%$ under acidification [20]. In most bivalve mollusks, there was an increase in standard metabolic rate following exposure to elevated $\mathrm{CO}_{2}$, which would increase the ATP levels [35]. Therefore, the increase of ATP in gill tissue demonstrated that the ATP production was accelerated in oyster to cover the increased energy expenditure of ion transport after 16 days' $\mathrm{CO}_{2}$ exposure. ATP is primarily produced by the energy machinery (mitochondria) and then it could be rapidly redistributed according to the energy charge $[43,44]$. In the present study, the ATP content in the purified mitochondria sample decreased significantly $(p<0.01)$ after $\mathrm{CO}_{2}$ exposure, indicating that the increasing ATP demand of ion-exchange in the cytoplasm after $\mathrm{CO}_{2}$ exposure accelerated the transport of ATP from the mitochondria to the cytoplasm. Collectively, the present results suggested that the gill tissue of oyster could stabilize energy charge by adjusting the ATP synthesis and allocating after $\mathrm{CO}_{2}$ exposure. As a result, more ATP produced inside the mitochondria would be transported to the cytoplasm to meet the demand of increasing ion transport.

In the present study, one CgsAC isoform of $45 \mathrm{kD}$ was confirmed to exist in mitochondria of oyster gill, which was suspected to be the truncated form of the $126-\mathrm{kD}$ band when it entered into the mitochondria according to our previous results [36]. The similar result has also been reported that sAC was truncated in the mitochondria of mouse liver (approximately $48 \mathrm{kD}$ ) [32]. In previous study, elevated $\mathrm{CO}_{2}$ was demonstrated to promote the accumulation of $\mathrm{HCO}_{3}{ }^{-}$ions in marine bivalves 
[35] and the elevation of bicarbonate could activate CgsAC and promote its truncation to increase cAMP synthesis in oyster gill tissue [36]. Moreover, sAC-dependent cAMP elevation in mitochondria promoted ATP production in mouse liver [45]. In the present study, the increase of ATP content in gill tissues and decrease in gill mitochondria caused by $\mathrm{CO}_{2}$ exposure could be both significantly inhibited by $\mathrm{KH}$, suggesting that $\mathrm{CgsAC}$ might not only play essential roles in promoting ATP synthesis or oxidative phosphorylation [32], but also in ATP translocation from mitochondria to cytoplasm. It indicated that the mitochondria-CgsAC signaling pathway might participate in resetting and optimizing the proper energy balance between enhanced ion transport and ATP metabolism.

In summary, elevated $\mathrm{CO}_{2}$ activated mitochondria-CgsAC pathway of apoptosis and ATP metabolism in oyster. As a bicarbonate regulated enzyme, CgsAC entered mitochondria and regulate apoptosis pathway and energy allocation. During $\mathrm{CO}_{2}$ exposure, accumulation of $\mathrm{HCO}_{3}{ }^{-}$ions in oyster activated $\mathrm{CgsAC}$ and trigger downstream mitochondria-CgsAC pathway in regulation of apoptosis and ATP metabolism to maintain internal balance in response to $\mathrm{CO}_{2}$ exposure and adapt to $\mathrm{OA}$ and it should be a strategy for oyster to live in such complex environment.

Acknowledgement: We thank all the laboratory members for continuous technical advice and beneficial discussions. This research was supported by National High Technology Research and Development Program (863 Program, No. 2014AA093501) from the Chinese Ministry of Science and Technology, and a grant (No. 31072192 to 
L.W.) from National Science Foundation of China.

\section{Reference}

[1] K.M. Kocot, J.T. Cannon, C. Todt, M.R. Citarella, A.B. Kohn, A. Meyer, S.R. Santos, C. Schander, L.L. Moroz, B. Lieb, Phylogenomics reveals deep molluscan relationships, Nature 477 (2011) 452-456.

[2] G.F. Zhang, X.D. Fang, X.M. Guo, L. Li, R. Luo, F. Xu, P. Yang, L. Zhang, X. Wang, H. Qi, Z. Xiong, H. Que, Y. Xie, P.W. Holland, J. Paps, Y. Zhu, F. Wu, Y. Chen, J. Wang, C. Peng, J. Meng, L. Yang, J. Liu, B. Wen, N. Zhang, Z. Huang, Q. Zhu, Y. Feng, A. Mount, D. Hedgecock, Z. Xu, Y. Liu, T. Domazet-Loso, Y. Du, X. Sun, S. Zhang, B. Liu, P. Cheng, X. Jiang, J. Li, D. Fan, W. Wang, W. Fu, T. Wang, B. Wang, J. Zhang, Z. Peng, Y. Li, N. Li, J. Wang, M. Chen, Y. He, F. Tan, X. Song, Q. Zheng, R. Huang, H. Yang, X. Du, L. Chen, M. Yang, P.M. Gaffney, S. Wang, L. Luo, Z. She, Y. Ming, W. Huang, S. Zhang, B. Huang, Y. Zhang, T. Qu, P. Ni, G. Miao, J. Wang, Q. Wang, C.E. Steinberg, H. Wang, N. Li, L. Qian, G. Zhang, Y. Li, H. Yang, X. Liu, J. Wang, Y. Yin, J. Wang,The oyster genome reveals stress adaptation and complexity of shell formation, Nature 490 (2012) 49-54.

[3] X. Song, H. Wang, L. Xin, J. Xu, Z. Jia, L. Wang, L. Song, The immunological capacity in the Larvae of Pacific oyster Crassostrea gigas, Fish Shellfish Immunol. 49 (2016): 461-469.

[4] Z. Jia, T. Zhang, S. Jiang, M. Wang, Q. Cheng, M. Sun, L. Wang, L. Song, An 
integrin from oyster Crassostrea gigas mediates the phagocytosis toward Vibrio splendidus through LPS binding activity, Dev. Comp. Immunol. 53 (2015) 253-264.

[5] G. Lannig, S. Eilers, H.O. Portner, I.M. Sokolova, C. Bock, Impact of ocean acidification on energy metabolism of oyster, Crassostrea gigas--changes in metabolic pathways and thermal response, Mar. Drugs 8 (2010) 2318-2339.

[6] A. Cherkasov, S. Grewal, I. Sokolova, Combined effects of temperature and cadmium exposure on haemocyte apoptosis and cadmium accumulation in the eastern oyster Crassostrea virginica (Gmelin), J. Therm. Biol. 32 (2007) 162-170.

[7] B. Michaelidis, D. Haas, M.K. Grieshaber, Extracellular and intracellular acid-base status with regard to the energy metabolism in the oyster Crassostrea gigas during exposure to air, Physiol. Biochem. Zool. 78 (2005) 373-383.

[8] O. Hoegh-Guldberg, P.J. Mumby, A.J. Hooten, R.S. Steneck, P. Greenfield, E. Gomez, C.D. Harvell, P.F. Sale, A.J. Edwards, K. Caldeira, N. Knowlton, C.M. Eakin, R. Iglesias-Prieto, N. Muthiga, R.H. Bradbury, A. Dubi, M.E. Hatziolos, Coral reefs under rapid climate change and ocean acidification, Science 318 (2007) 1737-1342.

[9] S.C. Fitzer, V.R. Phoenix, M. Cusack, N.A. Kamenos, Ocean acidification impacts mussel control on biomineralisation, Sci. Rep. 4 (2014) 6218.

[10] S.C. Doney, V.J. Fabry, R.A. Feely, J.A. Kleypas, Ocean acidification: the other $\mathrm{CO}_{2}$ problem, Annu. Rev. Mar. Sci. 1 (2009) 169-92.

[11] Q. Wang, R. Cao, X. Ning, L. You, C. Mu, C. Wang, L. Wei, M. Cong, H. Wu, J. 
Zhao, Effects of ocean acidification on immune responses of the Pacific oyster Crassostrea gigas, Fish Shellfish Immunol. 49 (2016) 24-33.

[12] S. Li, J. Huang, C. Liu, Y. Liu, G. Zheng, L. Xie, R. Zhang, Interactive effects of seawater acidification and elevated temperature on the transcriptome and biomineralization in the pearl oyster Pinctada fucata, Environ. Sci. Technol. 218 (2015) 3623-3631.

[13] A. Barton, B. Hales, G.G. Waldbusser, C. Langdon, R.A. Feely, The Pacific oyster, Crassostrea gigas, shows negative correlation to naturally elevated carbon dioxide levels: Implications for near-term ocean acidification effects, Limnol. Oceanogr. 57 (2012) 698-710.

[14] L.M. Parker, P.M. Ross, W.A. O'Connor, L. Borysko, D.A. Raftos, H.-O. Pörtner, Adult exposure influences offspring response to ocean acidification in oysters, Global Change Biol. 18 (2012) 82-92.

[15] A. Romero, B. Novoa, A. Figueras, The complexity of apoptotic cell death in mollusks: An update, Fish Shellfish Immunol. 46 (2015) 79-87.

[16] T. Kiss, Apoptosis and its functional significance in molluscs, Apoptosis 15 (2010) 313-321.

[17] S. Elmore, Apoptosis: a review of programmed cell death, Toxicol. Pathol. 35 (2007) 495-516.

[18] D. Liu, B. Yan, J. Yang, W. Lei, L. Wang, Mitochondrial pathway of apoptosis in the hepatopancreas of the freshwater crab Sinopotamon yangtsekiense exposed to cadmium, Aquat. Toxicol. 105 (2011) 394-402. 
[19] A.M. Pruski, D.R. Dixon, Effects of cadmium on nuclear integrity and DNA repair efficiency in the gill cells of Mytilus edulis L, Aquat. Toxicol. 57 (2002) 127-137.

[20] T.C. Pan, S.L. Applebaum, D.T. Manahan, Experimental ocean acidification alters the allocation of metabolic energy, Proc. Natl. Acad. Sci. U. S. A. 112 (2015) 4696-701.

[21] I.M. Sokolova, M. Frederich, R. Bagwe, G. Lannig, A.A. Sukhotin, Energy homeostasis as an integrative tool for assessing limits of environmental stress tolerance in aquatic invertebrates, Mar. environ. Res. 79 (2012) 1-15.

[22] W. Liu, M. He, Effects of ocean acidification on the metabolic rates of three species of bivalve from southern coast of China, Chin. J. Oceanol. Limnol. 30 (2012) 206-211.

[23] A.V. Ivanina, G.H. Dickinson, O.B. Matoo, R. Bagwe, A. Dickinson, E. Beniash, I.M. Sokolova, Interactive effects of elevated temperature and $\mathrm{CO}_{2}$ levels on energy metabolism and biomineralization of marine bivalves Crassostrea virginica and Mercenaria mercenaria, Comp. Biochem. Physiol. A Mol. Integr. Physiol. 166 (2013) 101-11.

[24] B. Hernroth, S. Baden, M. Thorndyke, S. Dupont, Immune suppression of the echinoderm Asterias rubens (L.) following long-term ocean acidification, Aquat. Toxicol. 103 (2011) 222-4.

[25] A.C. Wittmann, H.-O. Pörtner, Sensitivities of extant animal taxa to ocean acidification, Nature Clim. Change 3 (2013) 995-1001. 
[26] P. Seetharaman, K. Sarma, G. George, P. Krishnan, S.D. Roy, K. Sankar, Impact of coastal pollution on microbial and mineral profile of edible oyster (Crassostrea rivularis) in the coastal waters of Andaman, B. Environ. Contam. Tox. 95 (2015) $599-605$.

[27] L.L. Willson, L.E. Burnett, Whole animal and gill tissue oxygen uptake in the Eastern oyster, Crassostrea virginica: Effects of hypoxia, hypercapnia, air exposure, and infection with the protozoan parasite Perkinsus marinus, J. Exp. Mar. Biol. Ecol. 246 (2000) 223-240.

[28] S. Collins, K. McCoy, E.J. Catapane, M.A. Carroll, The effects of copper and copper blocking agents on gill mitochondrial $\mathrm{O}_{2}$ utilization of Crassostrea virginica, In Vivo 32(1) (2010) 14.

[29] S. Li, C. Liu, J. Huang, Y. Liu, S. Zhang, G. Zheng, L. Xie, R. Zhang, Transcriptome and biomineralization responses of the pearl oyster Pinctada fucata to elevated $\mathrm{CO}_{2}$ and temperature, Sci. Rep. 6 (2016) 18943.

[30] Y. Chen, M.J. Cann, T.N. Litvin, V. Iourgenko, M.L. Sinclair, L.R. Levin, J. Buck, Soluble adenylyl cyclase as an evolutionarily conserved bicarbonate sensor, Science 289 (2000) 625-628.

[31] M. Tresguerres, S.K. Parks, E. Salazar, L.R. Levin, G.G. Goss, J. Buck, Bicarbonate-sensing soluble adenylyl cyclase is an essential sensor for acid/base homeostasis, Proc. Natl. Acad. Sci. U. S. A. 107 (2010) 442-7.

[32] R. Acin-Perez, E. Salazar, M. Kamenetsky, J. Buck, L.R. Levin, G. Manfredi, Cyclic AMP produced inside mitochondria regulates oxidative phosphorylation, 
Cell Metab. 9 (2009) 265-76.

[33] A. Appukuttan, S.A. Kasseckert, M. Micoogullari, J.P. Flacke, S. Kumar, A. Woste, Y. Abdallah, L. Pott, H.P. Reusch, Y. Ladilov, Type 10 adenylyl cyclase mediates mitochondrial Bax translocation and apoptosis of adult rat cardiomyocytes under simulated ischaemia/reperfusion, Cardiovasc. Res. 93 (2012) 340-9.

[34] A. Appukuttan, S.A. Kasseckert, S. Kumar, H.P. Reusch, Y. Ladilov, Oxysterol-induced apoptosis of smooth muscle cells is under the control of a soluble adenylyl cyclase, Cardiovasc. Res. 99 (2013) 734-42.

[35] L.M. Parker, P.M. Ross, W.A. O'Connor, H.O. Portner, E. Scanes, J.M. Wright, Predicting the response of molluscs to the impact of ocean acidification, Biology 2 (2013) 651-92.

[36] X. Wang, M. Wang, Z. Jia, H. Wang, S. Jiang, H. Chen, L. Wang, L. Song, Ocean acidification stimulates alkali signal pathway: A bicarbonate sensing soluble adenylyl cyclase from oyster Crassostrea gigas mediates physiological changes induced by $\mathrm{CO}_{2}$ exposure, Aquat. Toxicol. 181 (2016) 124-135.

[37] J. Xu, S. Jiang, Y. Li, M. Li, Q. Cheng, D. Zhao, B. Yang, Z. Jia, L. Wang, L. Song, Caspase-3 serves as an intracellular immune receptor specific for lipopolysaccharide in oyster Crassostrea gigas, Dev. Comp. Immunol. 61 (2016) $1-12$.

[38] F. Gazeau, L.M. Parker, S. Comeau, J.-P. Gattuso, W.A. O’Connor, S. Martin, H.-O. Pörtner, P.M. Ross, Impacts of ocean acidification on marine shelled 
molluscs, Mar. Biol. 160 (2013) 2207-2245.

[39] H.R. Stennicke, J.M. Jürgensmeier, H. Shin, Q. Deveraux, B.B. Wolf, X. Yang, Q. Zhou, H.M. Ellerby, L.M. Ellerby, D. Bredesen, Pro-caspase-3 is a major physiologic target of caspase-8, J. Biol. Chem. 273 (1998) 27084-27090.

[40] I.-K. Wang, S.-Y. Lin-Shiau, J.-K. Lin, Induction of apoptosis by apigenin and related flavonoids through cytochrome c release and activation of caspase- 9 and caspase-3 in leukaemia HL-60 cells, Eur. J. Cancer 35 (1999) 1517-1525.

[41] A. Moya, E.L. Howes, T. Lacoue-Labarthe, S. Forêt, B. Hanna, M. Medina, P.L. Munday, J.S. Ong, J.L. Teyssié, G. Torda, Near future pH conditions severely impact calcification, metabolism and the nervous system in the pteropod Heliconoides inflatus, Global Change Biol. (2016).

[42] L.M. Turner, E. Ricevuto, A. Massa-Gallucci, M.-C. Gambi, P. Calosi, Energy metabolism and cellular homeostasis trade-offs provide the basis for a new type of sensitivity to ocean acidification in a marine polychaete at a high- $\mathrm{CO}_{2}$ vent: adenylate and phosphagen energy pools versus carbonic anhydrase, J. Exp. Biol. 218 (2015) 2148-2151.

[43] F.I. Ataullakhanov, V.M. Vitvitsky, What determines the intracellular ATP concentration, Bioscience Rep. 22 (2002) 501-511.

[44] M. Klingenberg, The ADP-ATP translocation in mitochondria, a membrane potential controlled transport, J. Membr. Biol. 56 (1980) 97-105.

[45] G. Di Benedetto, E. Scalzotto, M. Mongillo, T. Pozzan, Mitochondrial $\mathrm{Ca}^{2+}$ uptake induces cyclic AMP generation in the matrix and modulates organelle ATP 
levels, Cell Metab. 17 (2013) 965-975.

\section{Figure captions:}

Figure 1. Induction of apoptosis in hemocytes of oysters by different treatments. A-E: Representative dot plots for Annexin V-Alexa Fluor 488/Propidium Iodide (PI) staining in hemocytes of the control group ( $\mathrm{pH}=8.10)(\mathrm{A}), \mathrm{CO}_{2}$ exposure group $(\mathrm{pH}=7.50)$ (B), DMSO injection group $(\mathrm{pH}=7.50)(\mathrm{C}), 50 \mu \mathrm{mol} / \mathrm{kg} \mathrm{KH} 7$ group $(\mathrm{pH}=7.50)(\mathrm{D})$ and $5 \mu \mathrm{mol} / \mathrm{kg} \mathrm{KH7}$ group $(\mathrm{pH}=7.50)(\mathrm{E}) . \mathrm{F}$ : Quantitative graph of the data shown in A-E, indicating the changes of the proportion of early apoptotic and late apoptotic cells in hemocytes of different treatments. The results shown in $\mathrm{F}$ are means \pm SD from three technical replicates. Bars with lower-case letters indicated significantly different $(p<0.05)$.

Figure 2. Immunohistochemistry of CgsAC and mitochondria in oyster hemocytes of the control group $(\mathrm{pH}=8.10)$ and $\mathrm{CO}_{2}$ exposure group $(\mathrm{pH}=7.50)$. The nucleus of hemocytes was stained with DAPI (blue), immunoreactive signal of CgsAC was visualized by Alexa 488-labeled secondary antibody (green), immunoreactive signal of COX IV was visualized by Alexa 594-labeled secondary antibody (red) and the overlap of CgsAC with COX IV signal was visualized with yellow.

Figure 3. Western blotting of Cgcaspase-3 and $\beta$-tubulin in hemocytes of oysters under different treatments. 1: the control group ( $\mathrm{pH}=8.10), 2: \mathrm{CO}_{2}$ exposure group 
(pH=7.50), 3: DMSO injection group $(\mathrm{pH}=7.50)$, 4: $50 \mu \mathrm{mol} / \mathrm{kg} \mathrm{KH} 7$ group (pH=7.50), 5: $5 \mu \mathrm{mol} / \mathrm{kg} \mathrm{KH7}$ group $(\mathrm{pH}=7.50)$.

Figure 4. Effect of different treatments on hemocytes caspase-3/8/9 activity. A: caspase- 3 activity; B: caspase- 8 activity; C caspase- 9 activity. The results shown in A, $\mathrm{B}$, and $\mathrm{C}$ are means \pm SD from three technical replicates. Bars with lower-case letters indicated significantly different $(p<0.05)$.

Figure 5. Western blotting of CgsAC, $\beta$-tubulin and COX IV in gill tissue and mitochondria samples. 1: gill tissue sample, 2: gill mitochondria sample.

Figure 6. ATP content in gill tissue sample (A) and gill mitochondria sample (B). The samples were from oysters under different treatments: the control group $(\mathrm{pH}=8.10)$, $\mathrm{CO}_{2}$ exposure group ( $\left.\mathrm{pH}=7.50\right)$, DMSO injection group ( $\left.\mathrm{pH}=7.50\right), 50 \mu \mathrm{mol} / \mathrm{kg} \mathrm{KH} 7$ group $(\mathrm{pH}=7.50)$ and $5 \mu \mathrm{mol} / \mathrm{kg} \mathrm{KH} 7$ group $(\mathrm{pH}=7.50)$. ATP values in the tissue are $\mu$ moles ATP per gram tissue. ATP values in the mitochondria are nmoles ATP per milligram mitochondrial protein. The results shown in A and B are means \pm SD from three technical replicates. Bars with $*$ indicated significantly different $(p<0.05)$. 

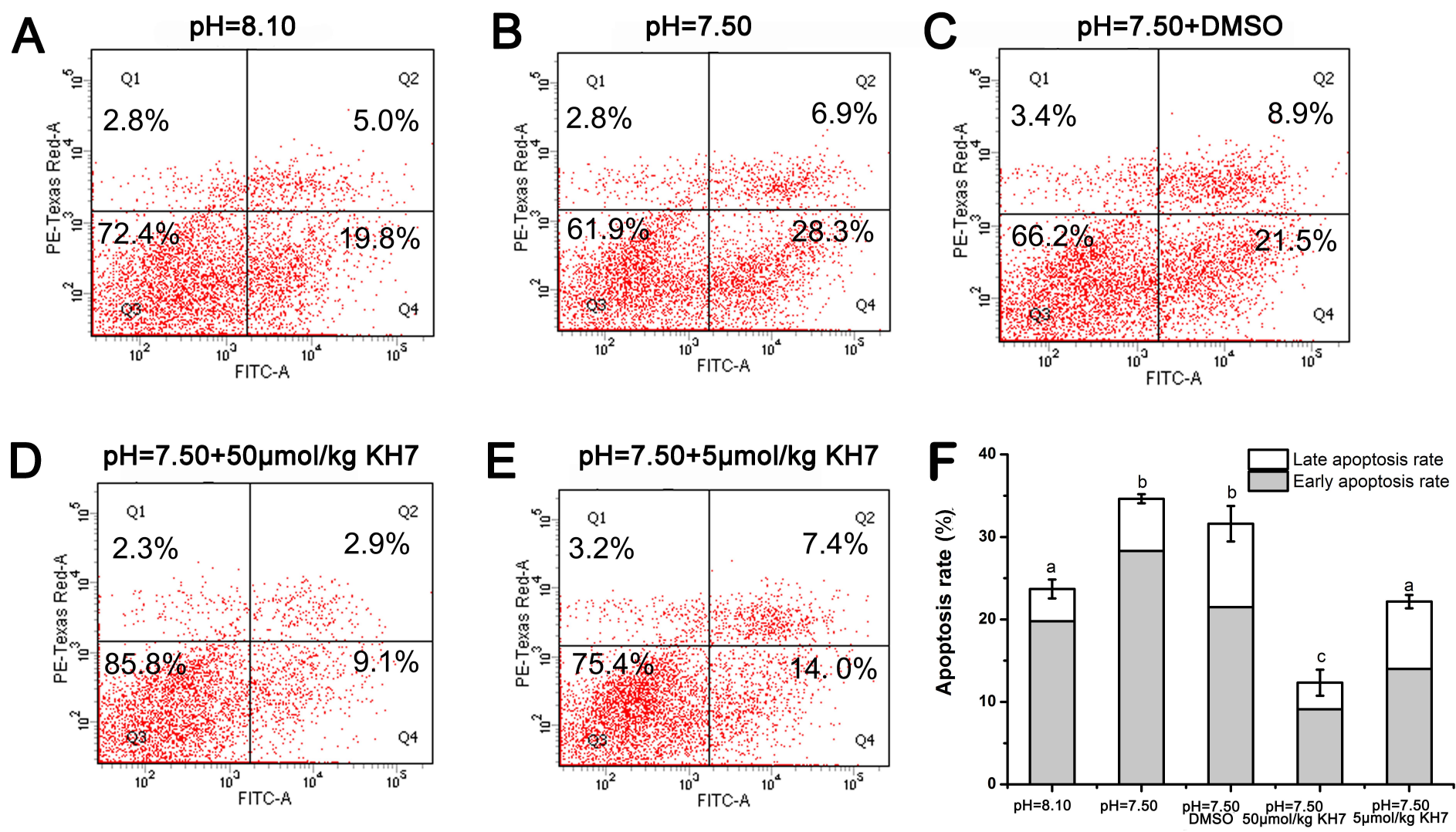
$\mathrm{pH}=8.10$ 


\section{$\beta$-tubulin 55 kD}

Pro-caspase-3 40 kD

Cleaved
caspase-3

Cleaved
caspase-3

$17 \mathrm{kD}$ 


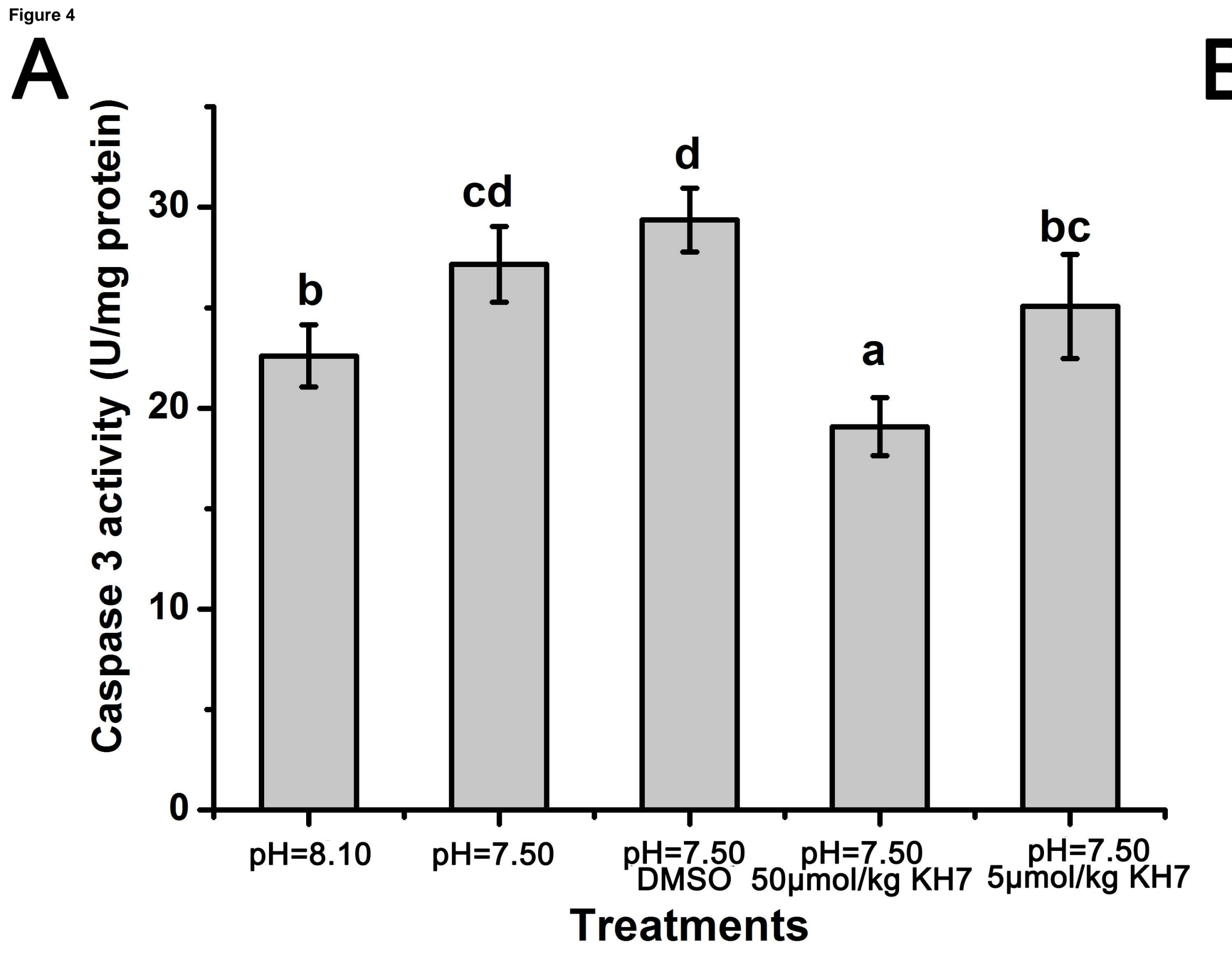

C
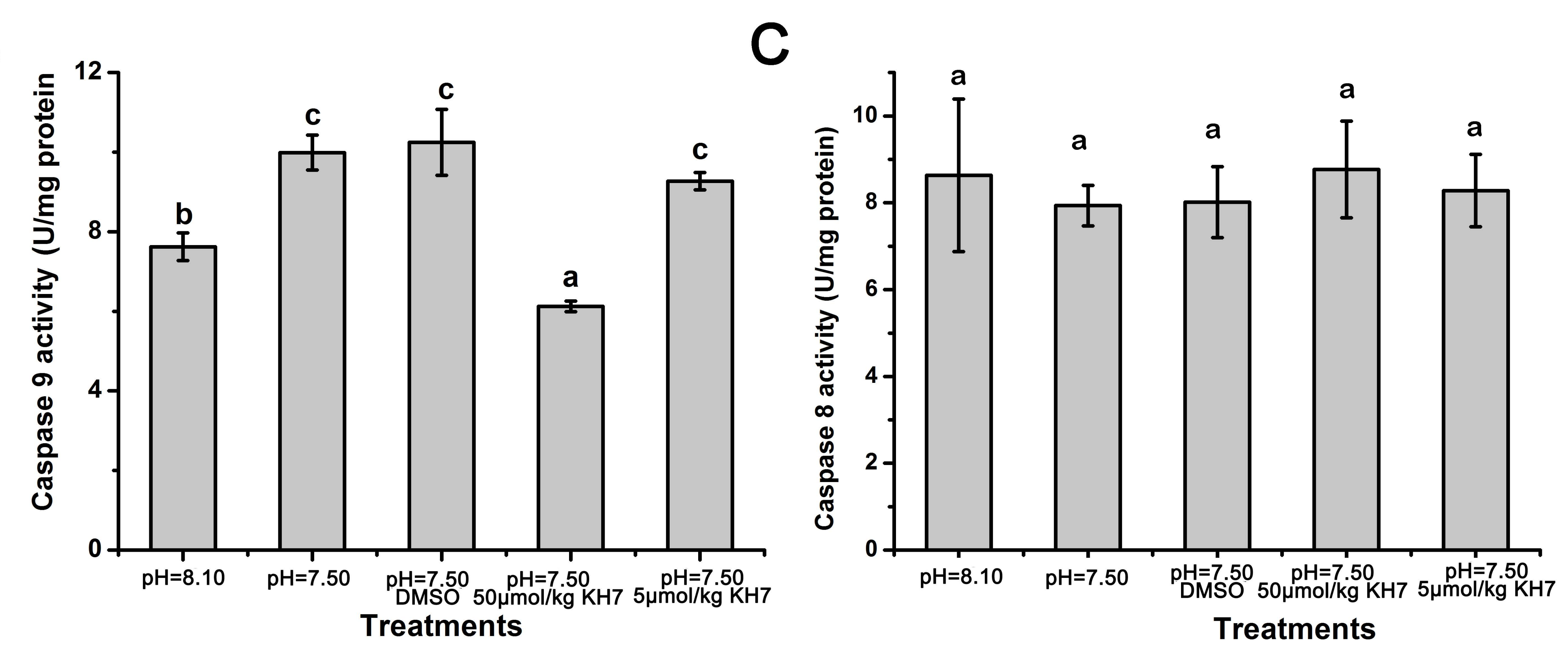


\section{Figure 512 \\ 126kD-}

45kD-

55kD-

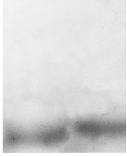

CgsAC

$\beta$-tubulin

20kD-
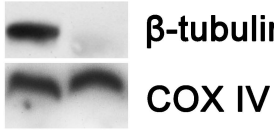


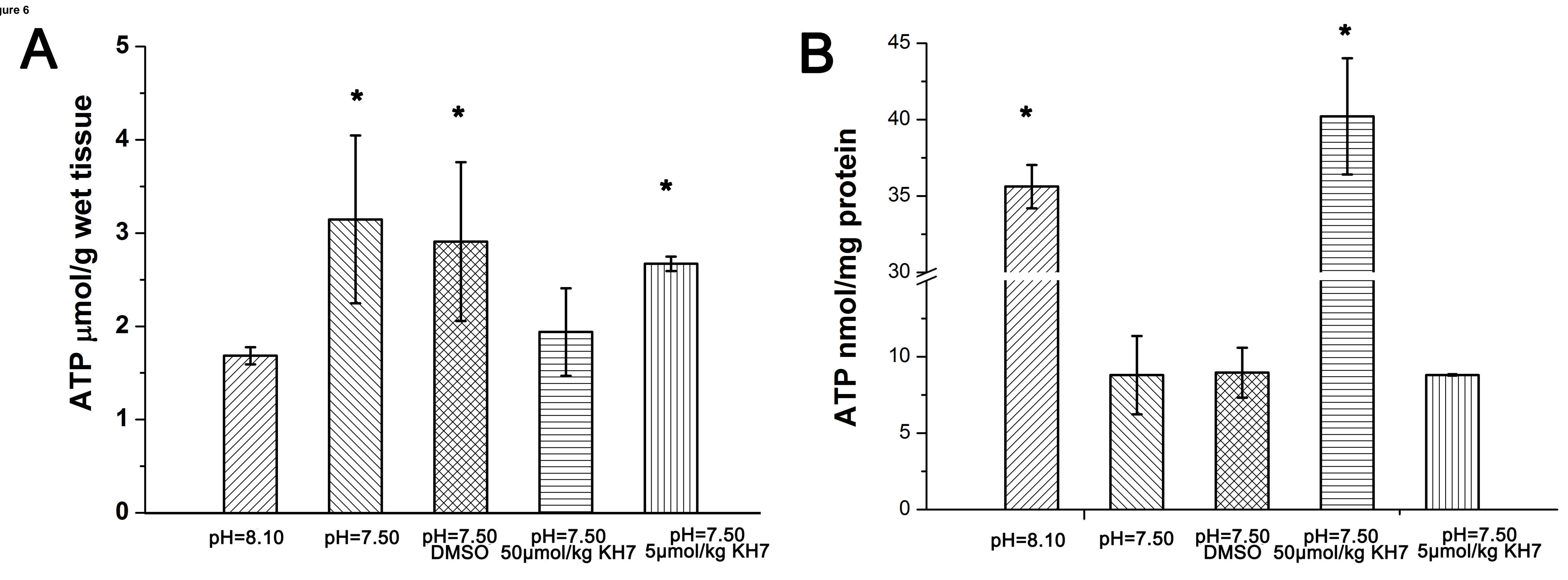

